\title{
CONTEMPORARIES FROM GÂNDIREA. SEPARATION FROM BLAGA
}

\author{
Ramona Șendrescu*, ORCID: 0000-0002-7256-330X \\ University of Craiova, Al. I. Cuza, Nr.13, Craiova, România \\ *Corresponding author: Ramona Șendrescu, ramona.sendrescu@edu.ucv.ro
}

Received: 06. 15. 2021

Accepted: 07. 26. 2021

\begin{abstract}
This paper is part of the PhD Thesis: Essays of Lucian Blaga and we want to show how the Romanian philosopher, one of the founders of the literary magazine „Gândirea”, the most published and admired author of this traditionalist journal, was only tolerated in the pages of "Gândirea” because he never accepted the concept of art and popular tradition stipulated in the ideological program imposed by Nichifor Crainic. The causes and the consequences of this separation can be found in Blaga's personal correspondence with his friends.
\end{abstract}

Keywords: culture, dogmatic, modernism, polemics, religion, tradition, spirituality.

Rezumat. Acest articol face parte din teza de doctorat: Eseistica lui Lucian Blaga. Dorim să arătăm cum filosoful român, unul dintre fondatorii revistei literare „Gândirea”, cel mai publicat și admirat autor al acestei reviste tradiționaliste, a fost doar tolerat în paginile „Gândirii” pentru că Blaga nu a acceptat niciodată conceptul de artă și tradiție populară stipulat în programul ideologic impus de Nichifor Crainic. Cauzele și consecințele acestei separări pot fi găsite în corespondența personală a lui Blaga cu prietenii săi.

Cuvinte cheie: cultură, dogmă, modernism, polemici, religie, tradiție, spiritualitate.

\section{Introducere}

Momentul Blaga în existenţa Gândirii înseamnă mai mult decât însuși Nichifor Crainic. Această primă observaţie concordă cu cea a lui Mircea Diaconu care consideră că „Blaga legitimează gândirismul. Tocmai de aceea nu credem că gândirismul trebuie limitat la ortodoxismul dogmatic propăvăduit de Crainic, cu atât mai mult cu cât impactul esteticii blagiene şi mai ales al poeziei lui a fost, în epocă, mult mai mare decât al ideologiei lui Crainic." [1, p. 54]

Filosoful clujean figurează printre fondatorii şi colaboratorii revistei încă de la primele sale numere. Gândirea apare la Cluj, în anul 1921, sub egida lui Cezar Petrescu și I. D. Cucu. Din anul 1922 revista se mută la București iar din 1926 este patronată de Nichifor Crainic.

Revista a apărut într-o perioadă de criză, în anii grei după război și devine importantă în peisajul cultural al vremii, chiar „una dintre cele mai bune reviste de după războiu” [2, p. 49 - 50] deoarece „Nici o publicaţie similară din ţară n-a grupat în jurul ei o pleiadă mai numeroasă de scriitori, cunoscători ai culturii europene." [3, p. 413] Personalități culturale publică la 
Gândirea pentru că în paginile revistei se promovau tradițiile, folclorul și mitologia românească.

\section{Relația lui Blaga cu contemporanii de la revista Gândirea}

Prima perioadă a revistei va fi rememorată de către Blaga în articolul Începuturile şi cadrul unei prietenii, apărut în Gândirea, din 1940, ca fiind „foarte tinerească”, „ca un buchet de tendinţe centrifuge, şi aproape ostentativ fără program”, „o manifestare cel mai adesea căutătoare, incertă (...), o manifestare reală dar fără manifeste”. În paginile ei domina „o atmosferă de colectivitate întemeiată pe prietenie în primul rând, iar nu pe o ideologie" [4, p. 223]. Revista arăta bine şi primele numere au avut mare succes. Tânărul ardelean se situează, încă de la începuturi, pe poziţii incerte faţă de mişcarea ce avea să devină în epocă o veritabilă instituţie culturală, aparţinând, după clasificarea pe care el însuşi a făcut-o cercului gândirist, aripii stângi a redacţiei. Blaga distingea o „dreaptă” a revistei” tradițional ortodoxistă unde sunt încadrați Nichifor Crainic, Vasile Voiculescu, Dumitru Stăniloaie, Ion Pillat şi o „stângă” a ei, unde se includea şi pe sine, „care punea accentul mai mult pe creaţie ”, (...) care „căuta noi şi iarăşi noi perspective pentru sufletele cu mai puţine aderenţe dogmatice” [4, p. 226], precum şi o direcţie „intermediară”. Conform lui Blaga în articolul publicat în Gândirea la aniversarea lui Nichifor Crainic, la dreapta Gândirii existau deosebiri. Deşi au susţinut întro oarecare măsură direcţiile programatice impuse de Nichifor Crainic, gânditori precum P.P. Ionescu, Ioan Coman, Vasile Băncilă sau Emilian Vasilescu nu au subscris niciodată programului politic recomandat de mentorul revistei.

Ruptura care intervenise în final, între Blaga şi Crainic, a fost anticipată de numeroase semne prevestitoare şi de disensiuni mai mult sau mai puţin mocnite, de natură ideologică şi de viziune asupra profilului revistei. Unele dintre ele se fac simțite după primii ani. De pildă, într-o scrisoare din 2 mai 1930, adresată lui Tudor Vianu, tânărul filosof îşi exprimă clar punctul de vedere diferit faţă de mentorul Gândirii: „Însuşi Nichifor Crainic a primit de la mine o serie de scrisori prin care ceream să nu limiteze programul Gândirei la «spiritualitatea ortodoxă»; visam ca acest program să fie simbolic - o verticală bipolară: spiritualitatea sus, adâncirea anonimului etnic jos (adâncirea etnicului ca rezultat al adâncirei în general şi nu ca rezultat al căutării etnicului). Ideologia aceasta am expus-o şi în Filosofia stilului, 1924 - (precum şi în alte articole). Ortodoxia e numai un caz al spiritualităţii spre care tinde apetitul metafizic al generaţiei noastre " [5, p. 91]. De altfel, distanţarea se produse, încă din vara lui 1926 când Blaga îi scria într-o scrisoare, trimisă din Polonia, lui Eugen Filotti, destăinuindu-i-se: „Ştii că în timpul din urmă am avut mari deziluzii cu prietenii de la Gândirea. Nu e exclus să-mi mut casa la Contemporanul. Ne-am găsi iarăşi în aceeaşi societate." [6, p. 125] Apoi, în 1933 părăsesc revista alţi doi fondatori, Adrian Maniu şi Cezar Petrescu. Din acest an revista trece în „tabăra” dreptei fasciste şi Blaga va tăia toate legăturile cu mişcarea gândiristă. Într-un fel, însuşi discursul de recepţie la Academie, Elogiul satului românesc, din 1937, era o formă de distanţare de ortodoxismul gândirist.

În 16 ianuarie 1940, când este invitat să colaboreze la numărul special dedicat lui Nichifor Crainic, Blaga ţine să se distanţeze şi mai categoric de doctrina susţinută de mentorul de la Gândirea. De aceea, mărturisea că nu poate trece de diferenţele de opinii ca sa poată scrie elogios despre Crainic: „Aş vrea să găsesc forma cea mai potrivită pentru a scrie ceva despre prietenia noastră, care a fost cea mai rodnică prietenie a vieţii mele. Nu pot, însă, să scriu despre ideologia lui Nichifor, fiindcă ar trebui s-o fac polemic, cum, de altfel, şi el, dacă ar scrie despre 
ideologia mea, ar face-o tot polemic, la ceea ce, de altfel, l-ar obliga şi catedra de apologetică." [6, p. 125].

Opinia noastră este că Lucian Blaga era considerat de Crainic, încă din momentul în care a luat conducerea revistei, ca un intrus pentru că niciodată filosoful ardelean nu a agreat concepţia ortodoxistă despre artă şi etnos. Ca o completare vine explicaţia din 1930 a mentorului Gândirii, în articolul După zece ani, unde precizează poziţia particulară a filosofului în gruparea ortodoxistă precum şi nota redacţiei care se delimita de opiniile filosofului la publicarea în paginile revistei a studiului Eonul dogmatic. De altfel, la noi persistă prejudecata că tot ce s-a publicat în revistă s-ar fi aliniat cu direcţia propusă de Crainic. Nimic mai neadevărat! Lucian Blaga este unul dintre autorii revistei cei mai publicaţi şi admiraţi. Conform opiniei lui Dumitru Micu, dacă prin cine ştie ce concurs de împrejurări toate volumele lui Blaga ar dispărea fără urmă, dar s-ar păstra, în schimb, întreagă, colecţia Gândirii, conceptele filosofiei sale ar putea fi reconstruite uşor pe baza fragmentelor publicate în revistă. „Despre nici un autor în viaţă, cu excepţia lui Nichifor Crainic, nu s-a scris în "Gândirea» atât de mult ca despre Lucian Blaga" [7, p. 352]. Nici o altă publicaţie a timpului nu va elogia mai mult pe filosof decât revista Gândirea. Amintim în acest sens numărul 8 al publicaţiei din decembrie 1934, în care, lui Blaga îi este dedicat un amplu grupaj de articole semnate de: Nichifor Crainic (Câteva notiţe despre Lucian Blaga), Tudor Vianu (Lucian Blaga, poetul), I. Brucăr (Filosoful Lucian Blaga), Emil Cioran (Stilul interior al lui Lucian Blaga), Dragoş Protopopescu (Lucian Blaga şi mitul dramatic), Vasile Băncilă (Lucian Blaga eseist).

Filosoful era receptat de către personalitățile culturii romane ca gândirist şi ortodoxist iar „aşteptările” de la el erau mari. Chiar şi G. Călinescu, în Istoria literaturii române, publicată în 1941, îl plasează pe Blaga la capitolul ortodoxişti, după Nichifor Crainic. Aşadar, membru fondator, figură proeminentă pe frontispiciul revistei şi prezenţă permanentă în Consiliul de redacţie de la primul număr până la ultimul - în ciuda rupturii care intervenise între timp, Lucian Blaga figura, prin excepţie alfabetică, cu numărul 1 în capul listei redacţionale a Gândirii, în caseta numelor de redactori şi colaboratori de bază. Acest lucru va fi menţinut neschimbat până la ultimul număr, iunie-iulie 1944, chiar dacă Blaga nu mai publicase articole în paginile revistei de trei ani, iar poezie şi eseuri de aproape şase.

La o privire de suprafață asupra momentului interbelic numele filosofului este lesne asociat cu imaginea revistei, devenit astfel, colaboratorul cel mai important, personalitatea fără de care mişcarea gândiristă nici nu poate fi imaginată. Numai că, pe măsură ce se împlinea sistemul filosofic, Blaga se plasa în tot mai evidentă contradicţie cu programul oficial, impus de Nichifor Crainic. Mulţi ani la rând, raporturile filosofului cu teoreticienii dogmei creştine de la Gândirea vor fi echivoce: el nu contestă explicit validitatea principiilor ortodoxiste, dar nici nu le elogiază în vreun fel. Atâta vreme cât filosoful nu contestă validitatea dogmei creştine s-a putut găsi şi păstra un anume modus vivendi, Nichifor Crainic considerându-l aliat în lupta împotriva raţionalismului de toate nuanțele.

Vasile Băncilă, un apropiat al lui Blaga, cât şi al cercului gândirist, martor care a luat parte la evenimente, reconstituie, în interviul acordat lui I. Oprişan, mediul, influenţele, relaţiile de orice tip care animă la un moment-dat gruparea. În acest context aminteşte de raporturile sinuoase dintre cei doi prieteni :,Crainic a fost destul de corect faţă de Blaga, fiindcă oricum, nu-i cerea Crainic lui Blaga să vorbească din punct de vedere al dogmei. Dar cel puţin dacă scrii la Gândirea nu critica dogma! Ai destule subiecte pe lumea asta, nu-i aşa? Nu-i nevoie să scrii chiar în Gândirea. (...) Ce-ar fi azi, de exemplu, Gândirea, dac-ar lipsi colaborarea lui Blaga? Şi pentru Blaga a folosit şi pentru Gândirea ... dar vezi că cu timpul ... Poate şi Crainic, câteodată a 
spus ce nu trebuia, căci Crainic era un temperament mai puternic decât Blaga" $[6$, p. 55].

După apariţia editorială a Diferenţialelor divine, Teologul Dumitru Stăniloae, ideolog de frunte al Gândirii, publica în 1940, în Telegraful român o amplă recenzie „consideraţiile noastre de ordin creştin", cu accente critice la cosmologia lui Lucian Blaga. Dumitru Micu, în studiul său Gândirea şi gândirismul constata lipsa de reacţie a gândiriştilor: „Apărută în 1940, e de mirare că Diferenţialelor divine, carte menită să intre în alcătuirea unei a patra trilogii cosmogonică - n-a făcut obiectul unei critici directe din partea ortodoxiştilor, ci doar al unor onctuoase rezerve, formulate de un colaborator extern, Ion Petrovici. " [7, p. 371]. La acea dată nici nu ar fi fost posibilă apariţia unei recenzii critice de virulenţa celei scrise de Dumitru Stăniloae, în Telegraful român şi în Revista teologică, pentru că relaţia dintre Nichifor Crainic şi Lucian Blaga era încă una foarte cordială. Va fi doar începutul unei polemici care va antrena pe durata mai multor ani, personalităţi marcante ale vremii, având ca rezultat clasificări teoretice şi delimitări ferme ale operei blagiene. Se năştea disputa dinte dogma creştină şi gândirea filosofică laică, aducând în actualitate problema creaţiei libere şi a statutului gânditorului. Aceste controverse asupra cosmogoniei se vor răsfrânge asupra întregului sistem filosofic blagian.

Crainic răbufneşte, în martie 1943, printr-un articol pamflet, Iulian Apostatul, în care îşi varsă, fără menajamente, ceea ce Ion Mihail Popescu cataloghează „râuri de invective rar întâlnite în scrisul românesc din toate timpurile." Pe scurt, Crainic face referire, fără a-l numi pe Blaga (aşa cum nici Stăniloae nu e numit direct în pamfletul Popa Grama), la vestitul împărat bizantin care, prin apostazie, a declarat război creştinismului, deşi era crescut, el însuşi, în spiritul acestei religii. Iulian Apostatul, notează Crainic, este într-un anumit sens, un etnicist, deoarece miturile pe care-şi clădea credinţa erau rezultatul geniului naţional al grecilor, geniu pe care-l vedea necontaminat de religia creştină.

Prin urmărirea schimbului de scrisori dintre cei doi se poate observa deteriorarea relației de prietenie care se încheie cu părăsirea revistei Gândirea de către Blaga și fondarea unei reviste proprii Saeculum. Reacţia lui Blaga nu întârzie. Atitudinea sa dusă până la extrem, va duce la ruptura de cercul gândirist, ruptură pentru care nu puţini îl acuză că a produs-o în momentul în care a reuşit să-şi formeze revista la Sibiu. Ecouri ale modului în care Lucian Blaga a primit eseul lui Crainic se regăsesc şi în corespondenţa particulară a filosofului, mai ales în scrisorile trimise Domniţei Gherghinescu. De altfel, chiar Blaga folosea apelativul Tiganul pentru a se referi la Crainic (în scrisoarea din 4 octombrie, 1941, Biblioteca Academiei Române, 148.383). Este regretabil că în corespondența particulară s-a ajuns la formulări vulgare și la exagerări verbale și nu s-a reușit păstrarea unui ton echilibrat. Nimeni nu-l va trata într-un chip mai caustic pe mentorul Gândirii şi e fără îndoială un indiciu al capriciilor destinului împrejurarea că semnatarul unor asemenea considerații îi era cel mai bun prieten. Este un derapaj trist care ar fi putut fi evitat, dovadă că Blaga nu purta polemicile în cel mai elegant mod.

Corneliu Blaga, văr de-al doilea cu filosoful, rememorează relaţia cu Nichifor Crainic şi distanţarea totală între cei doi. El se simte obligat să explice invectivele tari folosite de Blaga, folosind ca argument forte -„,bârfa.”: „Numele lui real era lon Dobre. Avea faciesul specific. Şi trăgea nişte chefuri la "Bandi»! Şi cu dame de calitate inferioară!", totuşi recunoaște exagerările făcute cu bunăştiinţă: „Eu merg prea departe, dar trebuia s-o spun, căci în definitiv Lucian Blaga a fost atacat atâta." [6, p. 116]. 
Pe o linie de centru se plasează mărturia lui Pan M. Vizirescu. Aceasta se coagulează în jurul unor nuclee (prietenia spirituală, traiectoria sinuoasă şi ruptura definitivă) analizate şi răs-analizate de ceilalţi interlocutori ai lui I. Oprişan. După Pan M. Vizirescu, punctul de plecare al disputei ar fi pornit de la afirmaţia lui Blaga cu privire la tatăl său, care deşi preot era ateu: „Chiar dacă a fost aşa, mărturia lui cade ca un blam. (...) Dar, în sfârşit, libertatea de gândire şi-a luat-o...Şi atunci Crainic, care era foarte irascibil, apărând ortodoxismul, a intrat în conflict cu Blaga, bunul său prieten." [6, p. 569].

Dincolo de explicaţiile contemporanilor, există şi o raţiune intrinsecă a acestei despărţiri de gruparea literară şi de mentorul ei. Mult discutata „ruptură” a lui Blaga de mişcarea gândiristă nu s-a datorat, cum au speculat unii contemporani sau cum a fost el însuşi, la un moment dat, tentat să se lase să creadă, unor divergenţe „politico-ideologice” ireductibile, cât orgoliului său lezat. Nu „pronazismul” lui Crainic (discutabil), de altfel, nici prolegionarismul altor colaboratori şi chiar lideri ai mişcării gândiriste, nici autohtonismul ortodox militant al revistei (pentru care nu avusese nicio obiecţie până atunci) nu-i va determina reacţia, ci critica pe care $D$. Stăniloae a făcut-o unor puncte vulnerabile ale sistemului său filosofic, invocând responsabilitatea teologului oficial (era pe atunci director al Telegrafului Român şi rector al Academiei Teologice Andreiane din Sibiu).

\section{Concluzii}

În finalul acestui studiu trebuie să sintetizez răspunsul la întrebarea dacă Lucian Blaga a aparținut scriitorilor de la revista Gândirea: despre Lucian Blaga se poate spune că era gândirist doar în măsura în care publicase în paginile revistei (poezii, articole de filosofie a culturii, fragmente din Trilogia cunoaşterii, precum şi din Artă şi valoare - care alături de Gândire magică şi religie şi Ştiinţă şi creaţie alcătuiesc Trilogia valorilor). „Găzduit” de redacţie, dacă nu chiar tolerat, el îşi va orienta gândirea într-o direcție opusă credințelor religioase gâdiriste, făcând evidentă observaţia lui Dumitru Micu despre gândirismul lui Blaga care „nu poate fi omologat cu acela al lui Crainic" [7, p. 362]. Afiliat deopotrivă de critica literară când modernismului când tradiționalismului și revendicat chiar și de avangardiștii putem considera că Blaga adoptă o atitudine neutră nelimitată ideologic. Putem afirma că acesta nu atacă tradiția ci o asimilează și revitalizează răspunzând la problemele existențiale moderniste prin soluții ca întoarcerea la liniștea naturii și la lumea mitică a satului.

\section{Referințe bibliografice:}

1. Diaconu M. Poezia de la Gândirea, Bucureşti: Editura Didactică şi Pedagogică, 1997.

2. Lovinescu E. Istoria literaturii române contemporane, Bucureşti: Socec1937.

3. Petrescu C. Zece ani. Pe când eram mai tineri, în „Gândirea”, an X, 12 decembrie 1930.

4. Blaga L. Începuturile şi cadrul unei prietenii, în: Gândirea, anul XIX-nr.4, aprilie 1940.

5. Tertulian N. Originalitate şi conformism, Scrisoare adresată de L. Blaga lui Tudor Vianu (1930) Manuscriptum, an X, nr. 1, 1979.

6. Oprişan I. Lucian Blaga printre contemporani, Editura Saeculum, Bucureşti, 1995.

7. Micu D. „Gândirea” şi gândirismul, Editura Minerva, Bucureşti, 1975. 